\title{
Physiological demands of a simulated BMX competition
}

\author{
J. Louis ${ }^{1}$, F. Billaut ${ }^{2}$, T. Bernard ${ }^{3}$, F. Vettoretti ${ }^{4}$, C. Hausswirth ${ }^{5}$, J. Brisswalter ${ }^{6}$ \\ ${ }^{1}$ Faculty of Sport Sciences, University of Nice Sophia Antipolis, Nice, France \\ ${ }^{2}$ School of Sport and Exercise Science, Victoria University, Melbourne, Institute of Sport, Exercise and Active Living, Melbourne, Australia \\ ${ }^{3}$ STAPS, University of South Toulon-Var, La Garde, France \\ ${ }^{4}$ CREPS Sud Est, French cycling federation, Aix en Provence, France \\ ${ }^{5}$ Research Department, INSEP, Paris, France \\ ${ }^{6}$ Laboratory of Human Motricity, Education Sport and Health, University of Nice Sophia Antipolis, Nice, France
}

Publié dans : International Journal of Sports Medicine, I-first 2012 ; DOI: 10.1055/s-0032-1327657

\begin{abstract}
The aim of the present study was to investigate the physiological demands of Supercross BMX during a simulated competition in elite athletes. During a preliminary session athletes underwent an incremental cycling test to determine maximal oxygen uptake $\left(\mathrm{VO}_{2 \max }\right)$ and power at ventilatory thresholds. In a second phase, athletes performed alone a simulated competition, consisting of six races separated by 30 minutes of passive recovery on an actual BMX track. During this simulated competition, oxygen uptake, blood lactate, anion gap and base excess (BE) were measured. Results indicated that a simulated BMX competition induces in elite athletes a high solicitation of both aerobic (mean peak $\left.\mathrm{VO}_{2}\left(\mathrm{VO}_{2 \text { peak }}\right): 94.3 \pm 1.2 \% \mathrm{VO}_{2 \max }\right)$ and anaerobic glycolysis (mean blood lactate: $14.5 \pm$ 4. $5 \mathrm{mmol} . \mathrm{L}^{-1}$ ) during every race. Furthermore, the repetition of six races separated by $30 \mathrm{~min}$ of recovery led to a significant impairment of the acid-base balance from the third to the sixth race (mean decrease in BE: $-18.8 \pm 7.5 \%, \mathrm{p}<0.05)$. A significant relationship was found between the decrease in $\mathrm{BE}$ and $\mathrm{VO}_{2 \text { peak }}(\mathrm{r}=-0.73, \mathrm{p}<0.05)$. These findings confirm the importance of anaerobic conditioning in BMX athletes, and highlight the importance of the oxidative pathway in this sport where repeated high-intensity efforts are required.
\end{abstract}

Keywords. Bicycle motocross, elite athletes, intermittent sprints, buffering capacity, aerobic demand, anaerobic glycolysis 


\section{Introduction}

Supercross BMX consists in the repetition of races on an irregular ground with turns and jumps. The length of the course is of approximately $350 \mathrm{~m}$, and each series lasts around $40 \mathrm{~s}$. During international events, a BMX cyclist that reaches the final has to perform 6 races with a recovery period of about 30 min between each race.

Few studies have analyzed the constraints of elite BMX and have focused mainly on biomechanical characteristics $[2,24,34]$. It is well established that during exercises lasting 10 to $40 \mathrm{~s}$ all the metabolic pathways are involved in a non-sequential way, including at the same time the degradation of phosphagenes, the degradation of the carbohydrates, and also the aerobic metabolism $[10,29]$. However, the power output developed during a BMX race is not constant and is characterized by peaks of maximum power and of short duration developed in particular during the initial phase of the race $[2,24]$. For example, Matteo et al. [33] have observed that during a BMX race simulation, acyclic efforts (i.e. non-pedaling efforts) accounted for $86.3 \%$ and cyclic efforts (i.e. pedaling efforts) accounted for the remaining $16.7 \%$ of the overall performance, with differences relating to the difficulty of the track. Thus, BMX performance is characterized by the capacity of the cyclist to produce a high level of muscular power at the beginning of the race, while displaying excellent technical skills with quasi isometric phases of work and some phases of exercise for which the muscular power of the lower limb must be again maximal. Other characteristics of Supercross BMX greatly distinguish this sport from sprint exercise models; a BMX cyclist is required to perform six races throughout the competition, and the relative contributions of the varied metabolic pathways in this specific situation has yet to be examined.

In this context, the purpose of our study was to investigate the physiological demands (i.e. aerobic and anaerobic energetic contribution) of BMX cycling during a simulated competition on an actual outdoor BMX track in elite athletes, in order to better identify the nature of recovery strategies needed during competition, as well as training programs for these athletes. 


\section{Materials and methods}

Subjects

Ten elite BMX cyclists (6 men and 4 women) who regularly compete at international level volunteered for this study. The characteristics of the athletes are shown in table 1 . The experiment took place in March just before the first international events in April. All subjects were informed about the study protocol, the risks of tests and investigations, and their rights according to the Declaration of Helsinki. The study was approved by the local Ethics Committee before its initiation, and was performed in accordance with the ethical standards of the International Journal of Sports Medicine [21]

Experimental procedure

The study was divided into two phases; one preliminary testing session and, one week later, a simulated BMX competition on the usual BMX training track where the athletes trained.

\section{Preliminary session}

Subjects underwent an incremental cycling test at a self-selected cadence on an electromagneticallybraked ergocycle (SRM, Schoberer Rad Messtecnik, Jülich, Welldorf, Germany). The test was performed in similar standard environmental conditions for all cyclists. The test began with a warm-up lasting $6 \mathrm{~min}$ at $100 \mathrm{~W}$, after which the power output was increased by $30 \mathrm{~W}$ every minute until volitional exhausted. During this incremental cycling exercise, oxygen uptake $\left(\mathrm{VO}_{2}\right)$, minute ventilation (VE), and respiratory exchange ratio (RER) were continuously measured with a breath by breath gas exchange analyzer (Cosmed K4b2, Roma, Italy). Gas and flow analyzers were calibrated prior to each test using gases of known concentration and a 3 L syringe (Hans Rudolph, Kansas City, $\mathrm{MO})$. The criteria used for the determination of $\mathrm{VO}_{2 \max }$ were a plateau in $\mathrm{VO}_{2}$ despite an increase in power output, a RER above 1.1, and a heart rate (HR) above $90 \%$ of the predicted maximal HR (Howley et al. 1995). $\mathrm{VO}_{2 \max }$ was determined from the four highest $\mathrm{VO}_{2}$ values recorded when $\mathrm{VO}_{2}$ reached a plateau, whilst the peak power output (PPO) was determined as the mean cycling power 
output recorded over the 1 min period equating with $\mathrm{VO}_{2 \max }$. The first and the second ventilatory threshold (VT1 and VT2) were determined according to the method described by Wasserman et al. $[31]$.

\section{Simulated BMX competition}

The cycling protocol was designed to reproduce as most as possible the physiological demand of a standard BMX international competition. The race course was a short outdoor track similar than that classically retrieved by participants in competition. Each race started from a $6 \mathrm{~m}$ high ramp followed by a 342-m hilly course with jumps, bumps and tightly banked corners. All cyclists individually performed 6 consecutive races separated by 30 min during which they were instructed not use any recovery strategy. Physiological measurements were performed immediately after each cycling race. Since the exercise was conducted in a challenging context for athletes (i.e. one month before the first international events), every athlete was well motivated to perform maximally the competition simulation. Competition was realized with a mean outdoor temperature of $17 \pm 0.7^{\circ} \mathrm{C}$ and wind lower than 3 knots.

Physiological assessment during the competition

Expired gases and oxygen uptake

Expired gases and oxygen uptake were measured immediately after every race using the K4b2 gas exchange system (Cosmed, Italy). The mask was applied on the face during $1 \mathrm{~min}$ immediately after the end of the race. The oxygen uptake recovery curve during the first $20 \mathrm{~s}$ was used to predict peak oxygen uptake $\left(\mathrm{VO}_{2 \text { peak }}\right)$ according to the method described by Carre et al. [13] and recently used to assess aerobic demand of sprint swimming [23].

Perceived exertion

Immediately after the expired gases measurement, perceived exertion was recorded using the 6-20 Borg scale ranging from very very light (6) to exhaustion (20) [14].

Blood sampling 
Blood lactate concentration (mmol. $\mathrm{L}^{-1}$ ) was measured before (baseline value) and 3 and 25 min after every race using the Lactate Pro analyzer (Arkray) validated by Tanner et al. [30]. The capillary blood samples $(5 \mu \mathrm{l})$ were collected from the finger.

Analysis of electrolytes changes (anion gap) and base excess was assessed using a portable clinical blood analyzer (i-STATTM, Abbott, Princeton, USA) [15]. Prior to each testing session, the i-STAT analyser was calibrated according to manufacturer's specifications by an electronic stimulation. Cartridges were stored prior to use as per manufacturers instructions $\left(2-8{ }^{\circ} \mathrm{C}\right)$, and were removed to cold approximately $5 \mathrm{~min}$ prior to use. Capillary samples were collected from each subject by fingerstick with a lancing device and balanced $100 \mu \mathrm{L}$ heparin capillary tubes at the end of the first, the third and the sixth race and during the recovery period at 5 min and 25 minutes. Prior to sampling, the puncture site was cleaned with alcohol and carefully dried by using surgical gauze. Each sample was immediately expelled from the capillary tubes into the sample wells of two $\mathrm{CG}^{+}$cartridges. Anion Gap was reported as the difference between measured cations sodium and potassium and anions chloride and bicarbonate. Base excess was calculated from $\mathrm{pH}$, partial pressure of carbon dioxide $\left(\mathrm{PCO}_{2}\right)$, and hemoglobin concentration $(\mathrm{Hb})$.

Statistical analysis

All data presented are means \pm SD (tables and figures). Each dependant variable was compared between the different cycling periods using an ANOVA with repeated measures (time). NewmanKeuls post-hoc tests were applied to determine between-means differences if the analysis of variance revealed a significant main effect for periods. Relationships between dependent variables $\left(\mathrm{VO}_{2}\right.$ peak, blood lactate, Anion Gap or Base excess at different period of the competition) were analyzed by a Pearson's correlation coefficient. In order to evaluate the magnitude of changes in recorded data for the different cycling periods, the coefficient of variation (CV) was also calculated. All statistical analyses were conducted using Statistica software version 7.0 (Statsoft, France). For all statistical analysis, a $\mathrm{P}<0.05$ value was accepted as the level of significance.

\section{Results}


Physiological characteristics of elite BMX cyclists recorded during the preliminary session are presented table 1.

\section{Performance}

In both experimental sessions, no significant effect of time was observed among the 6 races with values above $97 \%$ of best individual performance recorded during the 6 races and mean exercise duration of $32 \pm 4 \mathrm{~s}$ (figure 1a). Furthermore a good reproducibility of performance was observed across races with mean coefficient of variation $(\mathrm{CV})$ values of $2.7 \pm 0.2 \%$.

Physiological assessment during the competition

Parameters measured for each series are presented in Table 2.

Oxygen uptake response

No significant effect of time was observed on $\mathrm{VO}_{2 \text { peak }}$ values among the 6 series. Results indicated during a single BMX race lasting $32 \pm 4 \mathrm{~s}$, an important contribution of aerobic metabolism with $\mathrm{VO}_{2 \text { peak }}$ values higher than $90 \%$ of $\mathrm{VO}_{2 \max }$ (mean : $94.3 \pm 1.2 \% \mathrm{VO}_{2 \max }$ ) and for some subjects values reaching $100 \% \mathrm{VO}_{2 \max }$ (figure $1 \mathrm{~b}$ ).

\section{Perceived exertion}

No effect of time was observed on perceived exertion among the series. The mean perceived exertion was $16.2 \pm 0.9$, indicating a hard to very hard effort.

\section{Blood metabolic variables}

A high contribution from the anaerobic glycolysis assessed from blood lactate values was also observed with mean values of $14.5 \pm 4.5 \mathrm{mmol} . \mathrm{L}^{-1}$. Furthermore, after $25 \mathrm{~min}$ of recovery mean values of blood lactate were $5.4 \pm 1.2 \mathrm{mmol} . \mathrm{L}^{-1}$. No significant effect of time was observed on lactate values as well after races than at the end of recovery with intra-individual coefficient of variation (CV) values of: $8.3 \pm 4 \%$ (Figure $1 \mathrm{c}$ ). 
A significant main effect of time was observed for Anion Gap and BE $(\mathrm{p}<.05)$ with an increase in Anion Gap and decrease in Base Excess (BE) among races. Compared with resting baseline values, the increase becomes significant for Anion Gap after the third race whereas Base Excess values were significantly lower than baseline values for $\mathrm{BE}$ at the end of the first race and at the end of all the recovery periods. A further decrease in BE was observed at the end of the sixth race, when compared with the first one (Figure 2). A significant relationship $(\mathrm{r}=-0.73, \mathrm{p}<0.05)$ was found between $\mathrm{VO}_{2 \text { peak }}$ (expressed in $\% \mathrm{VO}_{2 \max }$ ) recorded during the last race and the decrease in $\mathrm{BE}$ from the first to the sixth series (delta BE)

\section{Discussion}

The main findings of the present study are that a simulated BMX competition in elite athletes elicits a high contribution from both aerobic and anaerobic glycolysis during every race despite the relatively short duration and non-constant power development during a race. Furthermore during a simulated BMX competition the repetition of six maximal sprints leads to a significant impairment of the acidbase balance from the third to the sixth race without any clear effect on performance.

The use of backward extrapolation to predict peak oxygen uptake was the only one that let the cyclists entirely free of their movements and realize all the technical elements of a BMX race (start, turns...). Using the same method for estimating $\mathrm{VO}_{2 \text { peak }}$, Jalab et al. [23] recently studied the dynamics of the aerobic response during a 100-m freestyle swim in well trained swimmers. Their results showed that $\mathrm{VO}_{2}$ increased very quickly at the beginning of race to reach $80 \%$ of the maximal aerobic power at 25 $\mathrm{m}, 94 \%$ at $50 \mathrm{~m}$ and $100 \%$ at $75 \mathrm{~m}$. Furthermore, high values of $\mathrm{VO}_{2}$ have been reached after $30 \mathrm{~s}$ of intensive cycling with a maximal starting power [18] and previous pacing studies have indicated that $\mathrm{VO}_{2}$ during maximal exercise can be increased by employing an all-out start [6] or a competition-start strategy [20]. This effect could be related to the greater phosphocreatine (PCr) breakdown at the onset of exercise when using a very fast start procedure [22]. BMX effort is mainly acyclic [24], and power output is developed by the lower limb predominantly during the first $10 \mathrm{~s}$ of the race. Thus, the relatively high percentage of $\mathrm{VO}_{2 \max }$ recorded at end-exercise suggests that the initial high metabolic demands have been carried over, presumably due to the energy required for technical work and 
isometric work of the upper limb. Such finding should be taken into account to design optimal training and recovery strategies. Furthermore, our result could also be related to the specificity of BMX training which is composed mainly of repeated sprints. Indeed, several studies have shown that the oxidative metabolism is critically taxed during repeated-sprint exercises, which influences performance [4, 28]. Furthermore, Bailey et al., [1] have shown that short-term training program involving repeated, all-out sprint training resulted in an enhanced fractional muscle $\mathrm{O}_{2}$ extraction (examined via near-infrared spectroscopy), faster $\mathrm{VO}_{2}$ kinetics, and an increased tolerance to highintensity exercise. Overall these results indicate for the first time an important aerobic contribution to the total energy provision in $\mathrm{BMX}$, suggesting that $\mathrm{VO}_{2 \max }$ could be one determinant of performance. However, a BMX race is also characterized by consecutive short-duration sprints probably performed at supra-maximal intensity, and involving other energetic pathways.

Factors affecting repeated sprint ability (RSA) have been widely studied in the last decade but for short-duration exercise ( $<10$ seconds), interspersed with brief recoveries ( $<60$ seconds) [3, 19]. In these studies one of most often suggested factor of RSA is the accumulation of $\mathrm{H}+$ (acidosis) that may impair performance through numerous mechanisms including inhibition of glycolytic enzymes such as phosphofructokinase, impairment of the contractile machinery through inhibition of $\mathrm{H}^{+}$on $\mathrm{CA}^{2+}$ binding to troponin or reduction of $\mathrm{CA}^{2+}$ reuptake and release. This hypothesis was supported by first studies demonstrating a correlation between RSA and both muscle buffer capacity and changes in blood $\mathrm{pH}[7,9]$. However, there are still many questions regarding the relationship between muscle performance and $\mathrm{pH}$ decrease or $\mathrm{H}+$ accumulation [25-26]. For example based on the notion that intracellular acidification is one of the major causes of fatigue several studies have tried to analyze the effect of ingested bicarbonate on exercise performance (e.g., Carr et al. [12]) and numerous studies were unable to validate the ergogenic effect of bicarbonate loading. Recently, in a laboratorysimulated BMX exercise composed by three Wingate tests separated either by 30 min recovery [33] or by $15 \mathrm{~min}$ recovery [32], the authors did not observe any effect of sodium bicarbonate ingestion on performance and perceived exertion. Furthermore, in our study despite a significant increase in anion gap after the third race and a significant decrease in base excess between the first to the last race, no 
effect was observed on performance in our elite athletes (figure 1a). The lack of any effect of time on performance recorded in this study could indicate that, in elite BMX cyclists, 30 min of recovery is enough to preserve maximal performance capacity throughout the competition. In the present study, the decrease in $\mathrm{BE}$ could be mainly related to the high contribution from anaerobic glycolysis assessed by blood lactate concentration values. These values measured after each series in the present study $\left(14.5 \pm 4.5 \mathrm{mmol}^{-1} \mathrm{l}^{-1}\right)$, are similar to experimental data recorded on 400-m runs [16, 27] $(13-16 \mathrm{mmol}$ $\left.1^{-1}\right)$. The lack of any period effect on blood lactate despite the decrease in base excess is in agreement with previous results indicating that the decrease in base excess is often larger than the increase in blood lactate [11]. Furthermore in our study we have recorded a significant relationship $(r=-0.73$, $\mathrm{p}<0.05$; figure 3) between peak $\mathrm{VO}_{2}$ (expressed in $\% \mathrm{VO}_{2 \max }$ ) recorded during the last race and the decrease in base excess from the first to the sixth series (delta $\mathrm{BE}$ ). Changes in $\mathrm{VO}_{2}$ explained $54 \%$ of the variation in $\mathrm{BE}$, which is in agreement with previous researches identifying a relationship between RSA and aerobic fitness [7, 17].These findings confirm the importance of aerobic conditioning in sports, where repeated high-intensity efforts are required, such as BMX $[5,8]$

\section{Conclusion}

These data, collected during a simulated competition on an outdoor BMX track, demonstrate for the first time that elite cyclists reach a very high relative $\mathrm{VO}_{2}$ during every race. Moreover, even in these world-class athletes, we observed a significant impairment in acid-base balance inversely related with aerobic metabolism solicitation. Thus, while specific training to maximize energy production from anaerobic sources should remain a significant part of the yearly plan, strategies to develop the oxidative pathway should certainly not be neglected in order to develop the full metabolic potential of BMX cyclists.

\section{References}

1 Bailey SJ, Wilkerson DP, Dimenna FJ, Jones AM. Influence of repeated sprint training on pulmonary O2 uptake and muscle deoxygenation kinetics in humans. J Appl Physiol 2009; 106: 18751887

2 Bertucci $W$, Hourde, C. Laboratory testing and field performance in BMX riders Journal of Sports Science and Medicine 2011; 10 417-419 
3 Billaut F, Bishop D. Muscle fatigue in males and females during multiple-sprint exercise. Sports Med 2009; 39: 257-278

4 Billaut F, Davis JM, Smith KJ, Marino FE, Noakes TD. Cerebral oxygenation decreases but does not impair performance during self-paced, strenuous exercise. Acta Physiol (Oxf) 2010; 198: 477-486

5 Billaut F, Smith K. Prolonged repeated-sprint ability is related to arterial O2 desaturation in men. Int J Sports Physiol Perform 2010; 5: 197-209

6 Bishop D, Bonetti D, Dawson B. The influence of pacing strategy on VO2 and supramaximal kayak performance. Med Sci Sports Exerc 2002; 34: 1041-1047

7 Bishop D, Edge J, Goodman C. Muscle buffer capacity and aerobic fitness are associated with repeated-sprint ability in women. Eur J Appl Physiol 2004; 92: 540-547

8 Bishop D, Girard O, Mendez-Villanueva A. Repeated-sprint ability - part II: recommendations for training. Sports Med 2011; 41: 741-756

9 Bishop D, Lawrence S, Spencer M. Predictors of repeated-sprint ability in elite female hockey players. J Sci Med Sport 2003; 6: 199-209

10 Bogdanis GC, Nevill ME, Boobis LH, Lakomy HK. Contribution of phosphocreatine and aerobic metabolism to energy supply during repeated sprint exercise. J Appl Physiol 1996; 80: 876-884

11 Boning D, Klarholz C, Himmelsbach B, Hutler M, Maassen N. Causes of differences in exerciseinduced changes of base excess and blood lactate. Eur J Appl Physiol 2007; 99: 163-171

12 Carr AJ, Hopkins WG, Gore CJ. Effects of acute alkalosis and acidosis on performance: a metaanalysis. Sports Med 2011; 41: 801-814

13 Carre F, Dassonville J, Beillot J, Prigent JY, Rochcongar P. Use of oxygen uptake recovery curve to predict peak oxygen uptake in upper body exercise. Eur J Appl Physiol Occup Physiol 1994; 69: 258-261

14 Chen MJ, Fan X, Moe ST. Criterion-related validity of the Borg ratings of perceived exertion scale in healthy individuals: a meta-analysis. J Sports Sci 2002; 20: 873-899

15 Dascombe BJ, Reaburn PR, Sirotic AC, Coutts AJ. The reliability of the i-STAT clinical portable analyser. J Sci Med Sport 2007; 10: 135-140

16 Duffield R, Dawson B, Goodman C. Energy system contribution to 400-metre and 800-metre track running. J Sports Sci 2005; 23: 299-307

17 Dupont G, McCall A, Prieur F, Millet GP, Berthoin S. Faster oxygen uptake kinetics during recovery is related to better repeated sprinting ability. Eur J Appl Physiol 2010; 110: 627-634

18 Gastin PB, Lawson DL. Variable resistance all-out test to generate accumulated oxygen deficit and predict anaerobic capacity. Eur J Appl Physiol Occup Physiol 1994; 69: 331-336

19 Girard O, Mendez-Villanueva A, Bishop D. Repeated-sprint ability - part I: factors contributing to fatigue. Sports Med 2011; 41: 673-694

20 Hanon C, Leveque JM, Thomas C, Vivier L. Pacing strategy and VO2 kinetics during a 1500-m race. Int J Sports Med 2008; 29: 206-211

21 Harriss DJ, Atkinson G. Update--Ethical standards in sport and exercise science research. Int $\mathrm{J}$ Sports Med 2011; 32: 819-821

22 Hirvonen J, Nummela A, Rusko H, Rehunen S, Harkonen M. Fatigue and changes of ATP, creatine phosphate, and lactate during the 400-m sprint. Can J Sport Sci 1992; 17: 141-144

23 Jalab C, Enea C, Delpech N, Bernard O. [Dynamics of oxygen uptake during a $100 \mathrm{~m}$ front crawl event, performed during competition ]. Appl Physiol Nutr Metab 2011; 36: 219-225

24 Mateo M, Blasco-Lafarga C, Zabala M. Pedaling power and speed production vs. technical factors and track difficulty in bicycle motocross cycling. J Strength Cond Res 2011; 25: 3248-3256

25 Overgaard K, Hojfeldt GW, Nielsen $O B$. Effects of acidification and increased extracellular potassium on dynamic muscle contractions in isolated rat muscles. J Physiol 2010; 588: 5065-5076

26 Pedersen TH, Nielsen OB, Lamb GD, Stephenson DG. Intracellular acidosis enhances the excitability of working muscle. Science 2004; 305: 1144-1147

27 Reis VM, Duarte, J.A., Espirto-Santo, J., Russel, A.P. . Determination of accumulated oxygen deficit during a 400-m run. Journal of Exercise Physiology 2004; 7: 77-83

28 Smith KJ, Billaut $F$. Influence of cerebral and muscle oxygenation on repeated-sprint ability. Eur J Appl Physiol 2010; 109: 989-999

29 Spencer MR, Gastin PB. Energy system contribution during 200- to 1500-m running in highly trained athletes. Med Sci Sports Exerc 2001; 33: 157-162 
30 Tanner RK, Fuller KL, Ross $M L$. Evaluation of three portable blood lactate analysers: Lactate Pro, Lactate Scout and Lactate Plus. Eur J Appl Physiol 2010; 109: 551-559

31 Wasserman K, Whipp BJ, Koyl SN, Beaver WL. Anaerobic threshold and respiratory gas exchange during exercise. J Appl Physiol 1973; 35: 236-243

32 Zabala M, Peinado AB, Calderon FJ, Sampedro J, Castillo MJ, Benito PJ. Bicarbonate ingestion has no ergogenic effect on consecutive all out sprint tests in BMX elite cyclists. Eur J Appl Physiol 2011; 111: 3127-3134

33 Zabala M, Requena B, Sanchez-Munoz C, Gonzalez-Badillo JJ, Garcia I, Oopik V, Paasuke M. Effects of sodium bicarbonate ingestion on performance and perceptual responses in a laboratorysimulated BMX cycling qualification series. J Strength Cond Res 2008; 22: 1645-1653

34 Zabala M, Sánchez-Muñoz, C. Mateo, M. . Effects of the administration of feedback on performance of the BMX cycling gate start. Journal of Sports Science and Medicine 2009; 8 393-400 
Table 1 Physical and physiological Characteristics of Elite BMX pilots.

\begin{tabular}{|l|l|l|}
\hline Variables & Males (n=6) & Female (n=4) \\
\hline Age (years) & $20.8 \pm 2.2$ & $19.0 \pm 2.2$ \\
\hline Height $(\mathrm{cm})$ & $177.3 \pm 9.7$ & $169.3 \pm 6.9$ \\
\hline Body mass (kg) & $75.4 \pm 3.3$ & $61.2 \pm 3.9$ \\
\hline Body mass index $\left({\left.\mathrm{kg} \cdot \mathrm{m}^{-2}\right)}^{-24.2 \pm 1.6}\right.$ & $21.4 \pm 1.4$ \\
\hline VO $_{2 \text { max }}\left(\mathrm{mL} \cdot \mathrm{min}^{-1} \cdot \mathrm{kg}^{-1}\right)$ & $54.7 \pm 4.7$ & $41.8 \pm 1.4$ \\
\hline Peak Power Output $(\mathrm{W})$ & $400.0 \pm 57.7$ & $280.0 \pm 10.0$ \\
\hline Power at VT1 $(\mathrm{W})$ & $212.5 \pm 14.4$ & $150.0 \pm 34.2$ \\
\hline Power at VT2 $(\mathrm{W})$ & $331.3 \pm 55.4$ & $200.0 \pm 25.2$ \\
\hline
\end{tabular}

Values are means \pm SD

$V T 1$ and $V T 2,1^{\text {st }}$ and $2^{\text {nd }}$ ventilatory threshold 
Table 2 Mean \pm SD values for parameters measured during the six sessions (S1 to S6) of the simulated BMX competition.

\begin{tabular}{|c|c|c|c|c|c|c|c|c|c|c|}
\hline & rest & \multicolumn{2}{|l|}{ R1 } & $\mathbf{R 2}$ & \multicolumn{2}{|l|}{ R3 } & R4 & R5 & \multicolumn{2}{|l|}{ R6 } \\
\hline $\begin{array}{l}\mathrm{VO}_{2 \text { peak }} \\
\quad\left(\% \mathrm{VO}_{2 \max }\right)\end{array}$ & & \multicolumn{2}{|l|}{$93.3 \pm 2.5$} & $94.2 \pm 3.1$ & \multicolumn{2}{|l|}{$97.4 \pm 1.5$} & $94.3 \pm 2.8$ & $93.1 \pm 3.2$ & \multicolumn{2}{|l|}{$94.5 \pm 3.1$} \\
\hline $\begin{array}{r}\text { Blood Lactate } \\
\left(\mathrm{mmol} \cdot \mathrm{L}^{-1}\right)\end{array}$ & $1.1 \pm 0.2$ & \multicolumn{2}{|l|}{$14 \pm 1.2^{*}$} & $15.8 \pm 1.4^{*}$ & \multicolumn{2}{|l|}{$15.3 \pm 0.8^{*}$} & $14.6 \pm 0.7^{*}$ & $14.2 \pm 1.1^{*}$ & \multicolumn{2}{|l|}{$13.9 \pm 0.8^{*}$} \\
\hline \multirow[t]{2}{*}{ RPE (6-10) } & & \multicolumn{2}{|l|}{$16.1 \pm 1.1$} & $16.2 \pm 0.8$ & \multicolumn{2}{|l|}{$16.3 \pm 1.2$} & $16.4 \pm 0.7$ & $16.2 \pm 1.2$ & \multicolumn{2}{|l|}{$16 \pm 0.9$} \\
\hline & rest & post $5 \mathrm{~min}$ & post $25 \mathrm{~min}$ & & post 5min & post $25 \mathrm{~min}$ & & & post 5min & post $25 \mathrm{~min}$ \\
\hline \begin{tabular}{|r} 
Base $\begin{array}{l}\text { excess } \\
\left(\mathrm{mmol} . \mathrm{L}^{-1}\right)\end{array}$ \\
\end{tabular} & $-1.8 \pm 0.3$ & $-15.2 \pm 3.2^{*}$ & $-6.8 \pm 2.5^{*}$ & & $-17.7 \pm 3^{*}$ & $-8.1 \pm 3.2^{*}$ & & & $-18.7 \pm 3^{* \$}$ & $-9.2 \pm 2.3^{*}$ \\
\hline $\begin{array}{r}\text { Anion Gap } \\
\left(\mathrm{mmol} . \mathrm{L}^{-1}\right)\end{array}$ & $14 \pm 4.5$ & $16.7 \pm 5.2$ & $15.1 \pm 4.8$ & & $22.7 \pm 4^{* \$}$ & $15.8 \pm 3.2$ & & & $23.4 \pm 3.6^{* \$}$ & $17.3 \pm 2.7^{* S}$ \\
\hline
\end{tabular}

${ }^{*}$ Significantly different from rest, ${ }^{\$}$ significantly different from the first race $(\mathrm{p}<.05)$ 
Figure 1: Performance (a), oxygen uptake (b), and blood lactate concentration (c) recorded at the end of the 6 sessions (S1-S6) of the simulated BMX competition. Values are means $\pm \mathrm{SD}$.
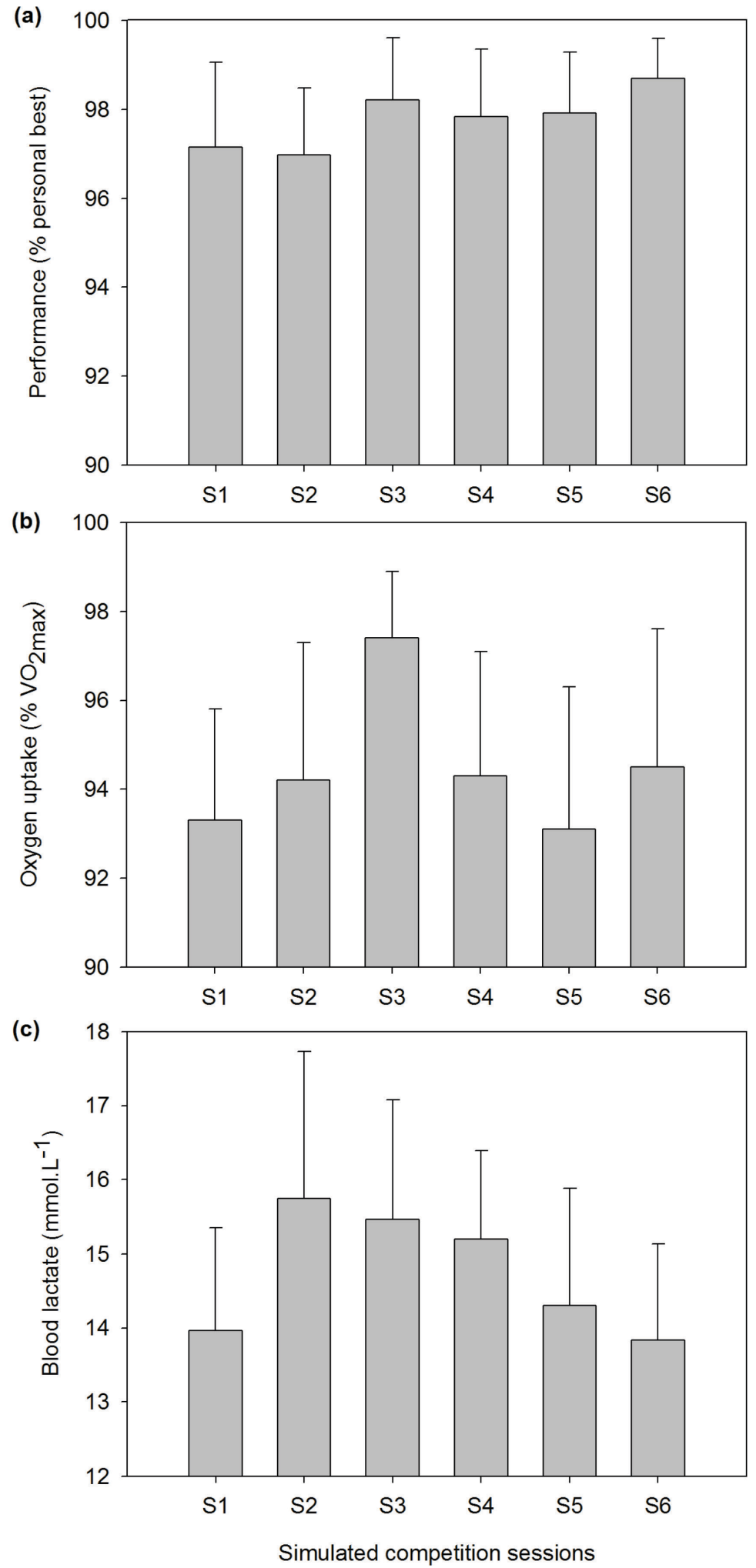
Figure 2: Changes in base excess (a) and anion gap (b) among the 6 sessions (S1-S6) of the simulated BMX competition. Values are means \pm SD.

* Significantly different from rest, \$ significantly different from the first session $(\mathrm{S} 1)(\mathrm{p}<.05)$


Recording times over the simulated competition 
Figure 3: Relationship between delta BE (Base Excess) calculated (in \%) between the last and the first session and peakVO $\left(\right.$ in $\% \mathrm{VO}_{2 \max }$ ) recorded during the last session of the simulated $\mathrm{BMX}$ competition.

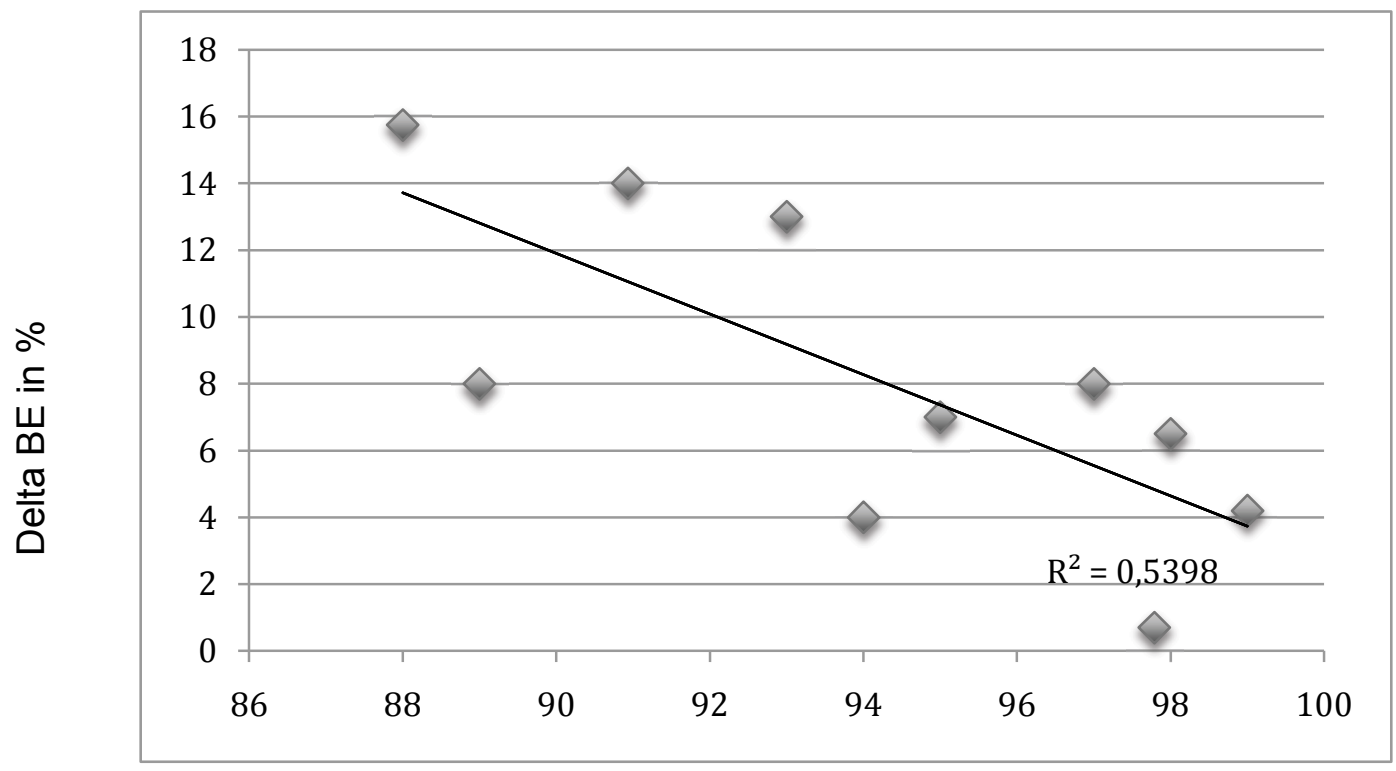

$\mathrm{VO}_{2 \text { peak }}$ in $\% \mathrm{VO}_{2 \max }$ 